\title{
Identifikasi Kadar dan Pengaruh Sifat Kimia Tanah terhadap Metabolit Sekunder Kunyit (Curcuma domestiva Val.) di Bangkalan
}

\author{
Diana Nurus Sholehah, Arief Amrullah, Kaswan Badami \\ Program Studi Agroteknologi, Fakultas Pertanian, Universitas Trunojoyo Madura \\ Email: diananurus@yahoo.co.id
}

\begin{abstract}
ABSTRAK
Penelitian ini bertujuan untuk mengidentifikasi kadar metabolit sekunder rimpang kunyit serta hubungannya dengan sifat kimia tanah di Kabupaten Bangkalan. Penelitian ini dilakukan pada bulan Maret-Juni 2015. Subyek penelitian ini adalah sentra penanaman kunyit milik kelompok tani di tiga kecamatan yang ada di Kabupaten Bangkalan tepatnya di Kecamatan Bangkalan, Kecamatan Galis, dan Kecamatan Geger yang ditetapkan berdasarkan metode purposive sampling. Sampel kunyit dan tanah diambil 12 tempat di masing-masing kecamatan yang ditetapkan berdasarkan snowball sampling. Rimpang kunyit yang diambil yaitu rimpang induk dan anakan dari tanaman kunyit umur 8-12 bulan, selanjutnya diukur berat kering dan kandungan metabolit sekundernya yaitu kurkumin dan minyak atsirinya sedangkan sampel tanah selanjutnya dianalisa kandungan $\mathrm{N}, \mathrm{P}, \mathrm{K}$ serta $\mathrm{C}$ organiknya. Data yang telah diperoleh kemudian di analisis menggunakan analisis regresi berganda. Hasil penelitian menunjukkan bahwa kunyit di Bangkalan memiliki berat kering rimpang 16,66 \% - 17,30\%, kandungan kurkumin 0,997 \% - 1,073\%, serta minyak atsiri 2,14 \% - 2,78 \%. Unsur $\mathrm{N}$ berkorelasi positif terhadap kandungan kurkumin sedangkan unsur $\mathrm{P}$ dan $\mathrm{C}$ organik berkorelasi positif terhadap berat kering kunyit. Sifat kimia tanah tidak memiliki pengaruh signifikan terhadap kandungan minyak atsiri kunyit.

Kata kunci : Kunyit, Bangkalan, kurkumin, minyak atsiri, tanah
\end{abstract}

\section{ABSTRACT}

This study aims to identify the levels of secondary metabolites turmeric and determine the influence of soil chemical properties of the secondary metabolites in Bangkalan. This study was conducted in March-June 2015. The study was conducted in turmeric cultivation centers belonging to farmer groups in three districts in Bangkalan precisely in the Bangkalan, Galis, and Geger district established by purposive sampling method. Turmeric and soil samples were taken 12 place in each district established by snowball sampling. main and tiller rhizome were taken at 8-12 months after planting than measured its dry weight and secondary metabolites content that is curcumin and essential oil yield, while soil samples were analyzed content of $N, P, K$ and $C$ organic. The data was analiyzed using multiple regression to find the relationship between the compounds curcumin turmeric with some soil chemical properties. The results showed that in Bangkalan turmeric rhizome has a dry weight of $16.66 \%-17.30 \%$, curcumin content of $0.997 \%-1.073 \%$, and the essential oil $2,14 \%-2,78 \%$. Soil nitrogen positively correlated to the content of curcumin while phosphor and organic $C$ soil was positively correlated to the weight of dry saffron.

Keywords: Turmeric, Bangkalan, curcumin, essential oil, soil 


\section{PENDAHULUAN}

Kunyit (Curcuma domestica Val.) merupakan salah satu dari tanaman obat unggulan nusantara yang memiliki banyak khasiat untuk pengobatan seperti antikoagulan, menurunkan tekanan darah, obat cacing, obat asma, penambah darah, mengobati sakit perut, penyakit hati, karminatif, stimulan, gatal-gatal, gigitan serangga, diare, rematik. Berdasarkan hasil survei tahun 2003, kebutuhan rimpang kunyit industri obat tradisional di Jawa Timur menduduki peringkat pertama, sedangkan di Jawa Tengah termasuk lima besar bersama-sama dengan bahan baku obat lainnya (Rahardjo dan Rostiana, 2005). Hal ini tidak mengherankan sebab kunyit mengandung metabolit sekunder kaya manfaat.

Rimpang kunyit mengandung senyawa utama yaitu minyak atsiri dan kurkumin selain demetoksikurkumin serta bisdemetoksikurkumin. Minyak atsirinya terdiri dari tumeron, tumerol, kariofilen, linalool dan sineol. Warna kuning kurkumin digunakan sebagai pewarna alami pada masakan tradisional. Selain itu juga dimanfaatkan sebagai pewarna kain seperti woll, katun dan sutera, kosmetika dan bahan indikator di laboratorium terhadap bahan-bahan yang mengandung alkali dan asam borat (Koswara, 2009).

$$
\text { Hasil survei }
$$

pertanian di Bangkalan tahun 2013, kunyit merupakan tanaman obat yang paling banyak ditanam oleh rumah tangga usaha hortikultura. Hal ini tidak mengherankan sebab menurut Handayani, dkk (1998), kunyit merupakan bahan utama hampir seluruh jenis ramuan jamu Madura khususnya jamu tradisional bagi wanita. Kunyit banyak ditanam oleh masyarakat baik untuk memenuhi kebutuhan rumah tangga maupun diusahakan secara komersial. Terdapat tiga Kecamatan yang mendominasi luas tanam kunyit antara lain Kecamatan Bangkalan dengan luas tanam $1.038 \mathrm{~m}^{2}$, Kecamatan Galis dengan luas tanam $20.950 \quad \mathrm{~m}^{2}$, dan Kecamatan Geger dengan luas tanam $10.000 \mathrm{~m}^{2}$.

Produktifitas dan mutu suatu tanaman dipengaruhi kombinasi faktor intrinsik yaitu genetik dan faktor ekstrinsik yaitu faktor lingkungan serta teknologi budidaya yang diterapkan. Menurut Kristina (2009), faktor lingkungan seperti lingkungan perakaran yang dipengaruhi sifat fisika dan kimia tanah berpengaruh terhadap metabolisme kunyit terutama metabolit sekundernya.

Penelitian ini bertujuan untuk mengidentifikasi kadar senyawa metabolit sekunder rimpang kunyit serta mengetahui pengaruh sifat kimia tanah terhadap kandungan metabolit sekunder di sentra penanaman kunyit kabupaten Bangkalan. Hal ini dapat bermanfaat untuk mengetahui potensi kunyit di Bangkalan sebagai bahan baku obat tradisional dan faktor-faktor yang mempengaruhinya berdasarkan sifat kimia tanah yang mempengaruhi sehingga dapat digunakan sebagai acuan untuk optimalisasi proses budidayanya.

\section{METODE PENELITIAN}

Penelitian ini dilakukan pada bulan Maret-Juni 2015. Bahan dan alat yang digunakan selama 
penelitian adalah rimpang kunyit, sampel tanah, bahan kimia untuk analisa sifat kimia tanah, kotak sampel, peralatan destilasi minyak atsiri dan analisa sifat kimia tanah.

Penelitian ini dilakukan di sentra penanaman kunyit milik kelompok tani di tiga kecamatan yang ada di Kabupaten Bangkalan tepatnya di Kecamatan Bangkalan, Kecamatan Galis, dan Kecamatan Geger yang ditetapkan dengan metode purposive sampling berdasarkan data luas tanam kunyit, tahun 2013 di Kabupaten Bangkalan. Sampel kunyit dan tanah diambil 12 tempat di masingmasing kecamatan yang ditetapkan berdasarkan snowball sampling. Rimpang kunyit yang diambil yaitu rimpang induk dan anakan dari tanaman kunyit umur 8-12 bulan. Rimpang yang telah diperoleh selanjutnya dianalisa kandungan metabolit sekundernya yaitu kurkumin dan minyak atsirinya sedangkan tanah yang telah diperoleh selanjutnya dianalisa kandungan $\mathrm{N}, \mathrm{P}, \mathrm{K}$ serta $\mathrm{C}$ organiknya di laboratorium BPKI
Surabaya.

Data yang telah diperoleh kemudian di analisis menggunakan analisis regresi berganda untuk mencari hubungan antara kandungan senyawa kurkumin rimpang kunyit dengan beberapa sifat kimia tanah (bahan organik tanah, kadar N, P, dan K) yang ada di Kabupaten Bangkalan.

\section{HASIL DAN PEMBAHASAN \\ Kandungan Metabolit Sekunder \\ Kunyit}

Kandungan metabolit sekunder yang diuji adalah metabolit sekunder utama yang terdapat dalam kunyit yaitu kurkumin dan minyak atsiri. Berdasarkan hasil penelitian, kandungan kurkumin kunyit di Bangkalan berkisar antara 0,997 \% $1,073 \%$ dengan kandungan tertinggi terdapat di kecamatan Galis yaitu $1,073 \%$ (Gambar 1). Kadar kurkumin di Bangkalan ini tergolong rendah dibandingkan hasil penelitian Wardiyati et al., (2012) yang meneliti kandungan kurkumin di daerah

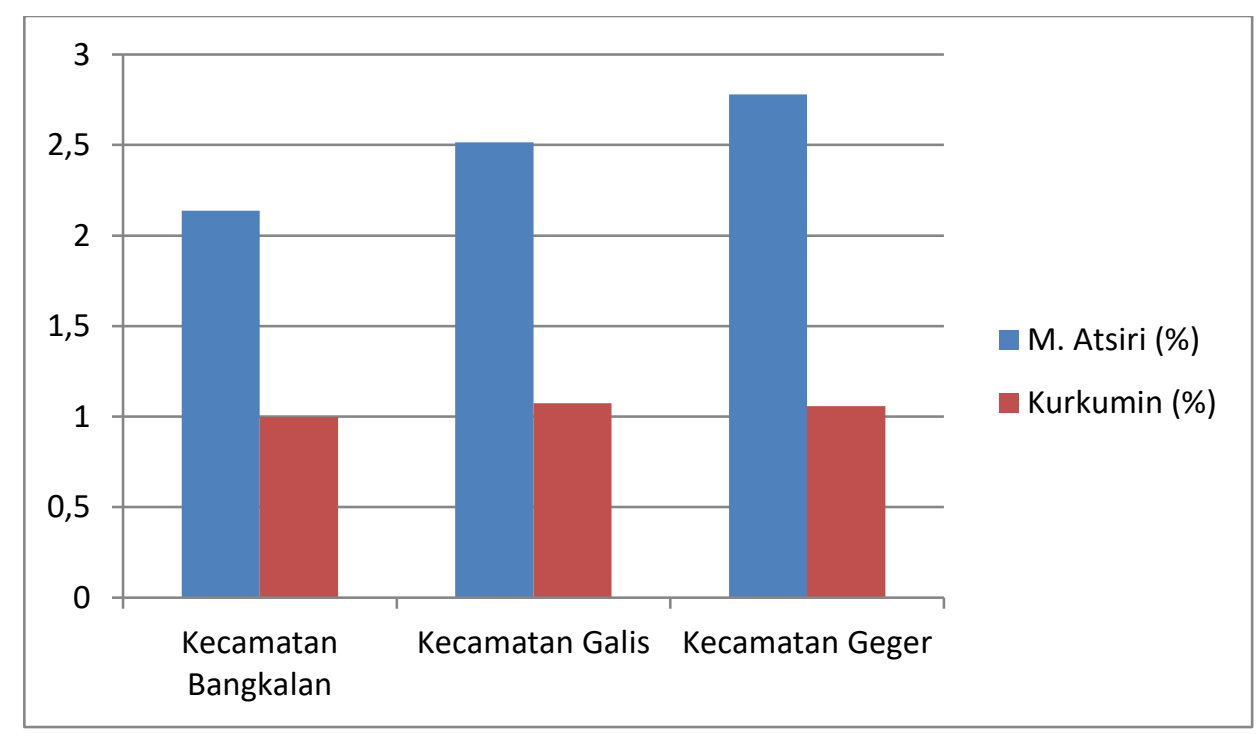

Gambar 1. Kandungan Metabolit sekunder kunyit di Bangkalan 


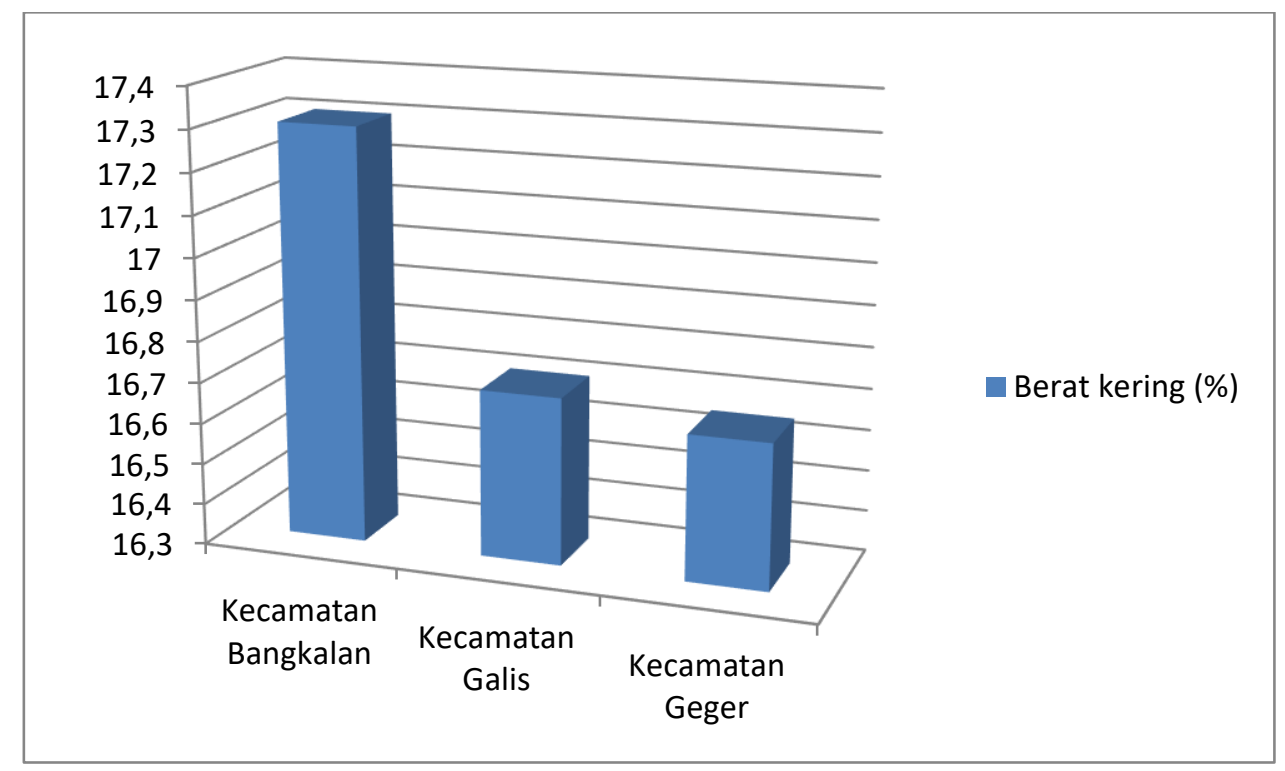

Gambar 2. Berat kering kunyit di Bangkalan

Madura lainnya yaitu Pamekasan $(2,75 \%)$ dan Sumenep $(2,90 \%)$. Kandungan minyak atsiri berkisar antara 2,14 \% - 2,78 \% dengan kandungan tertinggi terdapat di kecamatan Geger yaitu 2,78 \%. Kadar minyak atsiri tersebut lebih tinggi dibandingkan hasil penelitian minyak atsiri kunyit dari Surakarta yang berkisar $1,5-2,5 \%$ menurut Setyawan (2003). Secara geografis, kecamatan Galis dan Geger berada pada ketinggian tempat yang sama yaitu 46-49 mdpl lebih tinggi dibandingkan kecamatan Bangkalan yang berada pada ketinggian 5 mopl.

\section{Berat Kering Kunyit}

Berat kering kunyit berkisar antara 16,66 \% - 17,30 \% (Gambar 2). Berat kering tertinggi terdapat di Kecamatan Bangkalan yaitu 17,30 $\%$. Kadar bahan kering ini lebih tinggi dibandingkan kadar bahan kering di daerah lain di Pulau Madura yaitu Sumenep dan Pamekasan namun masih lebih rendah dibandingkan wilayah lain di Pulau Jawa seperti Mojokerto $(28,35$
$\%$ menurut hasil penelitian Wardiyati et al., (2012). Berat kering tanaman merupakan akumulasi senyawa organik hasil asimilasi $\mathrm{CO}_{2}$ selama periode tanam (Gardner, 2004).

\section{Sifat Kimia Tanah Bangkalan}

Kandungan unsur hara makro di Bangkalan (tabel 1) yaitu $\mathrm{N}$ dan $\mathrm{P}$ tergolong rendah sedangkan kandungan kalium dan C organik tergolong tinggi berdasarkan nilai sifat kimia tanah dalam Hardjowigeno (2003). Pemupukan belum dilakukan secara intensif, umumnya hanya bergantung pada pupuk organik kotoran ternak yang dipelihara petani dan seresah tanaman. Kecamatan Bangkalan memiliki kandungan unsur Kalium dan $C$ organik yang lebih tinggi dibandingkan kecamatan lain. Hal ini memungkinkan Kunyit yang berasal dari kecamatan Bangkalan memiliki berat kering yang lebih tinggi dibandingkan kecamatan lainnya. 
Tabel 1. Kandungan unsur hara di Bangkalan

\begin{tabular}{lcccc}
\hline Wilayah & $\mathbf{N}(\%)$ & $\begin{array}{c}\mathbf{P}_{2} \mathbf{O}_{5} \\
\mathbf{m e} / \mathbf{1 0 0}\end{array}$ & $\mathbf{K}_{2} \mathbf{O} \mathbf{~ m e} / \mathbf{1 0 0 g}$ & $\begin{array}{c}\mathbf{C} \text { Organik } \\
(\%)\end{array}$ \\
\hline $\begin{array}{l}\text { Kecamatan } \\
\begin{array}{l}\text { Bangkalan } \\
\text { Kecamatan }\end{array}\end{array}$ & 0,07 & 11,47 & 104,50 & 3,57 \\
$\begin{array}{l}\text { Galis } \\
\text { Kecamatan } \\
\text { Geger }\end{array}$ & 0,06 & 12,07 & 96,20 & 3,11 \\
\hline
\end{tabular}

Tabel 2. Koefisien korelasi sifat kimia tanah terhadap berat kering kunyit

\begin{tabular}{|c|c|c|}
\hline & Sifat kimia tanah & Koefisien korelasi \\
\hline $\mathrm{N}$ & & $-30,430$ \\
\hline$P$ & & $0,256^{*}$ \\
\hline K & & 0,040 \\
\hline C organik & & $1,314^{*}$ \\
\hline
\end{tabular}

$\left.{ }^{*}\right)$ signifikan

Tabel 3. Koefisien korelasi sifat kimia tanah terhadap kandungan metabolit sekunder kunyit

\begin{tabular}{|c|c|c|}
\hline \multirow[t]{2}{*}{ Sifat kimia tanah } & \multicolumn{2}{|c|}{ Koefisien korelasi } \\
\hline & & Minyak atsiri \\
\hline $\mathrm{N}$ & $0,265^{*}$ & 0,556 \\
\hline$P$ & $-0,150$ & $-0,002$ \\
\hline K & $-0,040$ & $-0,001$ \\
\hline C organik & $-0,125$ & $-0,026$ \\
\hline
\end{tabular}

$\left.{ }^{*}\right)$ signifikan

\section{Pengaruh sifat kimia tanah terhadap berat kering kunyit}

Hasil regresi berganda sifat kimia tanah terhadap berat kering kunyit memiliki nilai koefisien determinasi 0,853 atau 85,3 \%. Hal ini menunjukkan pengaruh variabel independen yaitu sifat kimia tanah dapat menjelaskan variabel dependen yaitu berat kering sebesar $85,3 \%$. Sedangkan $14,7 \%$ dijelaskan oleh variabel lain yang tidak dijelaskan dalam model. Berdasarkan tabel 2, kandungan $P$ dan C organik tanah memiliki korelasi positif terhadap berat kering kunyit. Hal ini sejalan dengan penelitian (Wardiyati, 2008) yang menyatakan bahwa unsur $P$ berkorelasi positif terhadap bobot rimpang dibandingkan terhadap kandungan kurkumin. Bahan organik berfungsi untuk mempertahankan kesuburan tanah dengan cara memelihara tekstur tanah, kelembaban, mensuplai hara dalam jumlah tertentu dan meningkatkan sifat biologi tanah sehingga dapat 
meningkatkan produktifitas tanaman (Widyasunu, 2002).

\section{Pengaruh sifat kimia tanah terhadap kandungan metabolit sekunder kunyit}

Hasil regresi berganda sifat kimia tanah terhadap kandungan kurkumin kunyit memiliki nilai koefisien determinasi 0,909 atau 90,9 \%. Hal ini menunjukkan pengaruh variabel independen yaitu sifat kimia tanah dapat menjelaskan variabel dependen yaitu kandungan kurkumin sebesar 90,9 \%. Sedangkan 9,1 \% dijelaskan oleh variabel lain yang tidak dijelaskan dalam model. Berdasarkan tabel 3, kandungan $\mathrm{N}$ tanah memiliki korelasi positif terhadap berat kering kunyit.

Kandungan metabolit sekunder kunyit dipengaruhi faktor genetik dan lingkungan. Kurkumin adalah hasil metabolit sekunder yang sangat dipengaruhi oleh kondisi lingkungan. Hal ini sesuai dengan pernyataan Wardiyati (2008) yang menyatakan dalam penelitiannya bahwa unsur hara $\mathrm{N}$ berkorelasi positif dengan kadar kurkumin. Dalam jalur pembentukan kurkumin diperlukan beberapa enzim seperti PAL (phenylalanine ammonia lyase) yang mengkatalisis perubahan phenilalanine menjadi asam sinamat. Enzim PAL akan meningkat aktivitasnya pada kondisi lingkungan yang ekstrim, seperti kadar nutrisi tanah yang rendah (Taiz dan Zeiger, 2007).

Hasil regresi berganda sifat kimia tanah terhadap kandungan minyak atsiri kunyit memiliki nilai koefisien determinasi 0,405 atau 40,5 \%. Hal ini menunjukkan pengaruh variabel independen yaitu sifat kimia tanah dapat menjelaskan variabel dependen yaitu kandungan kurkumin sebesar 40,5 \%.
Sedangkan 59,5\% dijelaskan oleh variabel lain yang tidak dijelaskan dalam model. Berdasarkan tabel 3 menunjukkan bahwa Sifat kimia tanah tidak memiliki pengaruh signifikan terhadap kandungan minyak atsiri kunyit. Menurut Yavari et al., (2010) kadar minyak atsiri pada tanaman Thymus vulgaris selain unsur hara juga dipengaruhi oleh beberapa faktor lingkungan seperti ketinggian dan iklim.

\section{KESIMPULAN}

1. Kunyit di Bangkalan memiliki berat kering rimpang 16,66 \% $17,30 \%$, kandungan kurkumin $0,997 \%-1,073 \%$, serta minyak atsiri $2,14 \%-2,78 \%$.

2. Unsur $\mathrm{N}$ berkorelasi positif terhadap kandungan kurkumin sedangkan unsur $P$ dan C organik berkorelasi positif terhadap berat kering kunyit. Sifat kimia tanah tidak memiliki pengaruh signifikan terhadap kandungan minyak atsiri kunyit.

\section{DAFTAR PUSTAKA}

Anonim, 2013. Potret usaha Pertanian Kabupaten Bangkalan menurut subsektor (Hasil Pencacahan Lengkap Sensus Pertanian 2013 dan Survei Pendapatan Usaha Rumah Tangga Pertanian 2013). BPS Kabupaten Bangkalan.

Gardner, F.P., R.B. Pearce, dan RL. Mitchell. 2008. Fisiologi Tanaman Budidaya Jakarta : Penerbit Universitas Indonesia. Hardjowigeno, S. 2003. Ilmu Tanah. Jakarta: Akademika Pressindo.

Koswara, S. 2009. Pewarna Alami Produksi dan Penggunaannya. Ebook Pangan. 
Kristina, Natali N., N. Rita, Syahid, S. Fatimah, dan R. Molide. 2009. Peluang Peningkatan Kadar Kurkumin pada Tanaman Kunyit dan Temulawak. Balai Penelitian Tanaman Obat dan Aromatik.

Lestari, H., Suharmiyati, Sakirno, S., Djoerban, B., Soegijono, K.R., Pranata, S. 1998. Inventarisasi Jamu Madura yang Dimanfaatkan untuk Pengobatan atau Perawatan Gangguan Kesehatan Berkaitan dengan Fungsi Reproduksi Wanita. Buletin Penelitian Sistem Kesehatan, 2(1), 41-54.

Rahardjo, M., dan Rostiana, Otih. 2005. Standar Prosedur Operasional Budidaya Tanaman Kunyit. Balai Penelitian Tanaman Obat dan Aromatika. Sirkuler, 11.

Setyawan, A, D. 2003. Keanekaragaman Kandungan Minya Atsiri Rimpang Temu- temuan (Curcuma). Jurnal Biofarmasi 1 (2), 44-49.

Taiz, L. dan E. Zeiger. 2007. Plant Physiology. Berlin : SpringerVerlag Berlin Heidelberg

Wardiyati, T, Yudi, R., Titik, S.A. 2008. Koleksi dan Identifikasi Temulawak (Curcuma xanthorrhiza Roxb.) dan Kunyit (Curcuma domestica Val.) di Jawa dan Madura. Jurnal IImuIImu Hayati, 20 (2), 159-164

Widyasunu, P. 2002. Manfaat Pupuk Organik bagi Pertanian Berkelanjutan. Makalah Pendidikan dan Pelatihan Pupuk Terpadu. Purwakarta: Fakultas Pertanian Universitas Jenderal Soedirman.

Yavari, A., Nazeri, V., Hassani M.E. 2010. Influence of some environmental factors on the essential oil variability of Thymus vulgaris. Nat Prod Commun, 5 (6), 943-948. 